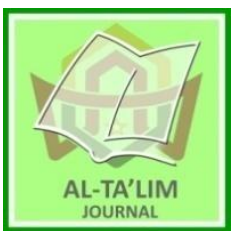

AL-TA'LIM JOURNAL, 26 (3), 2019, (233-242)

(Print ISSN 1410-7546 Online ISSN 2355-7893)

Available online at http://journal.tarbiyahiainib.ac.id/index.php/attalim

\title{
Measuring Students' Mathematical Literacy in Culturally Responsive Mathematics Classroom
}

Received: 05 ${ }^{\text {th }}$ April 2019; Revised: $06^{\text {th }}$ April 2019; Accepted: $30^{\text {th }}$ November 2019

Permalink/DOI: http://dx.doi.org/10.15548/jt.v26i3.551

\section{Ega Gradini*) \\ SekolahTinggi Agama Islam Negeri Gajah PutihTakengon, Indonesia \\ E-mail: ega.gradini@gmail.com}

\section{Firmansyah B}

SekolahTinggi Agama Islam Negeri Gajah PutihTakengon, Indonesia

E-mail: $\underline{\text { fmanb88@gmail.com }}$

\section{*) Corresponding Author}

\begin{abstract}
This paper aims to discuss students' mathematics literacy in culturally responsive mathematics classroom. Students were taught by culturally responsive mathematics material and examined with a series of test in order to measure their mathematics literacy level. The data collected in this study are quantitative data in the form of scores on students' mathematical abilities that indicate the level of student mathematics literacy. The research was conducted at MAN 1 Takengon with the two groups pre-test and post-test design to determine the differences in mathematical literacy skills of one experimental group and then compare the results with one control group that was not subjected to treatment. The test consists of 6 problems and designed by based on the domain of PISA 2015 questions on every level of mathematical proficiency skills. The research finds that (1) culturally responsive mathematic teaching gives positive effect to students' mathematical literacy; (2) the level of mathematical literacy of MAN 1 Takengon students lies from level 1 to level 5. There was no student who able to achieve $6^{\text {th }}$ level of mathematical literacy; and (3) After culturally responsive mathematics teaching was implemented, from 24 students, there were 4 students at $1^{\text {st }}$ level, 7 students at $2^{\text {nd }}$ level, 10 students at $3^{\text {rd }}$ level, and 2 students at $4^{\text {th }}$ level, and 1 student at $5^{\text {th }}$ level of mathematical literacy.
\end{abstract}

Keywords: Mathematical literacy; culturally responsive; teaching of mathematics.

How to Cite: Gradini, E., \& Firmansyah, F. (2020). Measuring students' mathematical literacy in culturally responsive mathematics classroom. Al-Ta Lim Journal, 26(3). doi:http://dx.doi.org/10.15548/jt.v26i3.551

\section{INTRODUCTION}

Mathematics no longer a tool but human activities (Morgan, 2001). It is crucial to teach mathematics as an activity that is relevant to the real conditions e.g students' daily life. There were some pedagogical theories that support culturally-relevant teaching in a critical paradigm and through an explicit relationship between student culture and students' knowledge. In this perspective, it is necessary to integrate culturally relevant curricula in existing mathematics one.
According to (Lobo \& Torres-Velasquez, 2005), this perspective is an important component of culturally responsive teaching. The theory proposes that teachers contextualize mathematics learning by connecting mathematical content with students' real-life culture and experience. In mathematics, the idea of culturally responsive teaching has been conceptualized by (Ambrosio, 2014) as ethnomatematics, which is defined as the study of mathematics that considers and integrates the culture in which mathematics arises or how different cultures 
"carry out the task of classifying, sorting, measuring or democratizing their environment". (Ambrosio, 2014; Rosa \& Orey, 2011; Rosa, Orey, Rosa, \& Orey, 2003) proposed that the culturally-relevant mathematics curriculum must focus on the role of mathematics in the socio-cultural context involving ideas and concepts related to ethnomathematics then deploy its perspectives to solve contextual problems.

Teaching mathematics in Indonesia still embraced teacher centered learning and dependent on textbooks, thus limiting teacher creativity when teaching. Students memorize the procedure for solving the problems, not the concept. Therefore, they were unable to solve a mathematics problem that required understanding. PISA 2015 placed Indonesia at rank 62 from 73 countries where girls perform better than boys in all subjects tested: Science, Language, and Mathematics. However, the performance of Indonesian students (girls and boys) in Science, Mathematics and Reading is one of the lowest among PISA participating countries (Shiel, Kavanagh, \& Millar, 2014; Stacey, 2011). Efforts to improve the quality of Mathematics learning must not only be limited to discourse, but the real action is also needed throughout Indonesia. Currently, mathematics learning in Indonesia tends to be too dry, theoretical, less contextual, and abstract. The teaching is less varied, thus affecting students' interest in learning mathematics. Furthermore, mathematics teaching is too formal, hence mathematics that children find in everyday life is very different from what they taught at school. Meanwhile, it is necessary to provide culturally-relevant mathematics in the classroom.

One of the strengths that students bring into the classroom is a cultural capital. Theoretically, teachers can use students' cultural capital to stimulate mathematics learning or even ignore it, actively motivate students to want to learn or even add to the burden of achievement. This shows that teachers have a strategic role as agents of socialization. The teacher can use the cultural background of students to teach mathematics.

The relationship between mathematics and culture has been studied through the study of ethnomathematics. The history of the emergence of a mathematical theorem and symbols is related to certain cultural backgrounds; such as Roman numerals, Arabic numerals, Pythagorean (Greek) theorems and solutions to the Al Khwarizmi (Iraq) quadratic equation. Mathematical ideas have been used in all cultures in historical and contemporary contexts. (Averill et al., 2009) used the idea by integrating the ethno mathematics context in everyday life of the Brazilian community to help students understand mathematics while understanding their community. Another example that shows the relationship between mathematics and culture is (Gerdes, 1988) who showed how to develop the ideas of Euclidean geometry using geometric constructions developed from traditional Mozambican culture. Indonesia itself has various cultural wealth, therefore it is possible to explore the ethnomathematics contained in it.

From the perspective of the mathematics curriculum, Gutstein (2003) investigates deeper into the effects on students' mathematics learning by experimenting with immigrant students from Latin America, low-income students, and studying in urban schools as subjects. With instructional curriculum and design, he intends to enable students to study the world through mathematics, foster mathematical abilities, and change students' attitudes towards mathematics. In order to connect mathematics learning and life experiences of students, Gutstein (2003) did not only choose the book "Mathematics in Context", but also designed mathematical questions that were in accordance with reality. After two years of implementation, students can demonstrate their ability to solve problems with varied methods, and with effective communication.

This paper discussed students' mathematics literacy in culturally responsive mathematics classroom. Students were taught by culturally responsive mathematics material 
and examined with a series of test in order to measure their mathematics literacy level. This study deploy 6 levels of mathematics literacy suggested by PISA.

Culturally responsive teaching is defined as a teaching approach that uses students' cultural knowledge as a 'channel' to facilitate the teaching-learning process ((Educators, 1999); Ladson-Billings, 1994; Villegas \& Lucas: 2002;(Herron \& Barta, 2009)). Ladson-Billings (1994) and Pewewardy (1994) in their research on responsive cultural teaching have reported positive effects on student learning.

Ukpokodu (2011) in his studies on culturally responsive teaching found that: 1) generally, teachers see mathematics as culturally-neutral (not influenced by culture). This view explains that mathematics is an abstract subject, "universal language," whose numbers are the same throughout time, culture, and space. Therefore, teaching mathematics has nothing to do with culture. But in its development, Ukpokodu (2011) saw that teachers actually understood that mathematics was not culturally neutral, absolute, or universal. Instead, it lies within the socio-cultural framework of certain cultural groups. Therefore, most researchers on culturally responsive teaching in mathematics have suggested that different cultures have different ways of thinking and doing mathematics than others. Thus, students from different cultural backgrounds enter the learning process with their cultural thinking and style when working on mathematics, and the teacher must understand the phenomena. 2) The convenience and dominance of textbook-based mathematics learning. Like most other subjects, mathematics teaching is directed by teachers and based on textbooks. The teacher views that to fulfill the curriculum; learning must be based on textbooks, which ultimately makes it difficult for teachers to think outside and about culturally responsive math instruction. The teacher also believes that failure to follow mandated curriculum material can put him in trouble. 3) Standardize curriculum and examinations. The teacher feels pressured to increase student exam scores and finally teaches for the exam. Since it focuses on increasing test scores, many teachers feel limited and powerless to teach in a culturally responsive way to meet the needs of their students. 4) The lack of mathematical teaching model that is culturally responsive to emulate. The teacher states that culturally responsive teaching is a new concept for them. Some of the phrases used to describe this ignorance include: "not informed", "never seen", and "never heard it."

Other studies also found teachers' misguided beliefs about culturally responsive mathematics teaching. Mukhopadyay and Greer (2001) found that teachers argue that teaching culturally responsive mathematics means that teachers foster different understandings that begin with the belief that mathematics is a human activity based on human culture and "their efforts to describe and understand physical and social phenomena". In a culturally responsive teaching, the teacher must believe that mathematics and culture can be integrated into learning. This is an important aspect of teaching culturally responsive mathematics (Ukpokodu, 2011). Integrating relevant cultural content in teaching mathematics is very difficult and challenging for teachers. In his description of multicultural education, (Banks, 1992) explains the integration of multicultural content means the use of examples, metaphors, and perspectives from different cultural frames when examining concepts, theories, paradigms, etc. Studies conducted by Bandeira and Lucena (2004) focused on the influence of cultural factors on teaching and learning in mathematics classroom. Dossey (1990); Rosa et al. (2003) argue that the results of mathematical knowledge from social interactions where relevant ideas, facts, concepts, principles, and skills are obtained as a result of cultural contexts.

In a culturally responsive classroom, the teacher focuses on guiding students, meaningful negotiators, and facilitating 
students in exploring, analyzing, and drawing conclusions. The teacher must refrain from becoming authoritarian and the only source of information for students. The teacher must also be able to design an active, creative, and interesting learning process. To learn mathematics by introducing the local culture, teachers can do this by delivering mathematical material about culture. (Ukpokodu, 2011) suggests various strategies for teaching culturally responsive mathematics, namely: 1) Building trust and relationships among students by making them often work in partnerships and small groups; 2) Using heterogeneous grouping structures based on race, gender, ability, language, etc. 3) Teach democratic values and behavior, rules, and participation roles; and 4) Create complex learning tasks with many parts that allow each group member to have a part that contributes to the overall goal of the activity.

In agreement with Ladson-Billings (1995), Ukpokodu (2011) suggested that the practice of culturally responsive mathematics teaching must begin with teachers setting high expectations for all students, respecting students, and being responsible if their students did not achieve, creating motivation by demystifying mathematics as neutralculture, and design student learning to ensure their success. (Averill et al., 2009) suggested that culturally responsive mathematics teaching requires teacher self-critiques and practice questions that enable them to gain insight. PISA defines mathematical literacy as 'individual's capacity to formulate, employ, and interpret mathematics in a variety of contexts. It includes reasoning mathematically and using mathematical concepts, procedures, facts and tools to describe, explain and predict phenomena. It assists individuals to recognize the role that mathematics plays in the world and to make the well-founded judgments and decisions needed by constructive, engaged and reflective citizens" (Johar, 2012; Shiel et al., 2014; Stacey, 2011). This conception of mathematical literacy supports the importance of students developing a strong understanding of concepts of pure mathematics and the benefits of being engaged in explorations in the abstract world of mathematics.

\section{METHOD}

This study was conducted with the two groups pre-test and post-test design to determine the differences in mathematical literacy skills of one experimental group and then compare the results with one control group that was not subjected to treatment. Culturally responsive mathematics teaching is conducted by applying local culture context to a problem-based learning model.

The data collected in this study are quantitative data in the form of scores on students' mathematical abilities that indicate the level of student mathematics literacy. Students were taught by culturally responsive mathematics material and examined with a series of test that deploy local culture in order to measure their mathematics literacy level. The test consist of 6 problems and designed by based onthe domain of PISA 2015 questions on every level of mathematical proficiency skills. The problems involved four over-arching ideas; namely (1) change and relationship, (2) Space and Shape), (3) Quantity, and (4) Uncertainty and data, and four contexts; namely (1) personal, (2) occupational, (3) societal, and (4) scientific (OECD in Johar, 2015).

Table 1. The domain of Problems on Test

\begin{tabular}{|c|c|}
\hline $\begin{array}{c}\text { Problem } \\
\text { No }\end{array}$ & Domain of Problems \\
\hline 1 & $\begin{array}{l}\text { Content : Change and Relationship } \\
\text { Context : Occupational } \\
\text { Process : Employ }\end{array}$ \\
\hline 2 & $\begin{array}{l}\text { Content : Change and relationship } \\
\text { Context : personal } \\
\text { Process : Employ }\end{array}$ \\
\hline 3 & $\begin{array}{l}\text { Content : Change and relationship } \\
\text { Context : Scientific } \\
\text { Process : Employ }\end{array}$ \\
\hline 4 & $\begin{array}{l}\text { Content : Space and Shape } \\
\text { Context : Societal } \\
\text { Process : Interpret }\end{array}$ \\
\hline 5 & $\begin{array}{l}\text { Content : Quantity } \\
\text { Context : Occupational } \\
\text { Process : Employ }\end{array}$ \\
\hline 6 & $\begin{array}{l}\text { Content : Uncertainty and Data } \\
\text { Context : Scientific } \\
\text { Process : interpret }\end{array}$ \\
\hline
\end{tabular}


Table 2. Descriptions of The Six Levels of Proficiency on the PISA 2015 Mathematical Literacy Scale

\begin{tabular}{|c|c|}
\hline $\begin{array}{l}\text { Level and Score } \\
\text { Range }\end{array}$ & Students at this level are capable of: \\
\hline $6(669+)$ & $\begin{array}{l}\text { Conceptualising, generalising and using information based on their investigations and } \\
\text { modelling of complex problem situations; using knowledge in relatively non-standard } \\
\text { contexts; linking different information sources and representations and moving flexibly } \\
\text { among them; applying their insight and understanding, along with mastery of } \\
\text { symbolic and formal mathematical operations and relationships, to develop new } \\
\text { approaches and strategies for addressing novel situations; reflecting on their actions and } \\
\text { formulating and precisely communicating their actions and reflections regarding their } \\
\text { findings, interpretations and arguments, and explaining why they were applied to the } \\
\text { original situation. Students at this level are able to successfully complete the most } \\
\text { difficult PISA items. }\end{array}$ \\
\hline $5(607-668)$ & $\begin{array}{l}\text { Developing and working with models of complex situations, including identifying } \\
\text { constraints and specifying assumptions; selecting, comparing and evaluating appropriate } \\
\text { problem-solving strategies for dealing with complex problems related to these models; } \\
\text { working strategically using broad, well-developed thinking and reasoning skills, } \\
\text { appropriate linked representations, symbolic and formal characterizations and insights } \\
\text { pertaining to these situations; beginning to reflect on their work and formulating and } \\
\text { communicating their interpretations and reasoning }\end{array}$ \\
\hline $4(545-606)$ & $\begin{array}{l}\text { Working effectively with explicit models of complex, concrete situations that may } \\
\text { involve constraints or making assumptions; selecting and integrating different } \\
\text { representations (including symbolic representations) and linking them directly to aspects } \\
\text { of real-world situations; using their limited range of skills and reasoning with some } \\
\text { insight in straightforward contexts; constructing and communicating explanations and } \\
\text { arguments based on their interpretations, arguments and actions. }\end{array}$ \\
\hline $3(482-544)$ & $\begin{array}{l}\text { Executing clearly described procedures, including those that require sequential decisions; } \\
\text { making sufficiently sound interpretations to be a base for building a simple model or for } \\
\text { selecting and applying simple problem-solving strategies; interpreting and using } \\
\text { representations based on different information sources and reasoning directly from them; } \\
\text { showing some ability to handle percentages, fractions and decimal numbers, and to work } \\
\text { with proportional relationships; engaging in basic interpretation and reasoning. }\end{array}$ \\
\hline $2(420-481)$ & $\begin{array}{l}\text { Interpreting and recognising situations in contexts that require no more than direct } \\
\text { inference; extracting relevant information from a single source and make use of a single } \\
\text { representational mode; employing basic algorithms, formulae, procedures or conventions } \\
\text { to solve problems involving whole numbers; making literal interpretations of the results. }\end{array}$ \\
\hline $1(358-419)$ & $\begin{array}{l}\text { Answering questions involving familiar contexts where all relevant information is } \\
\text { present and the questions are clearly defined; able to identify information and to carry } \\
\text { out routine procedures according to direct instructions in explicit situations; can perform } \\
\text { actions that are almost always obvious and follow immediately from the given stimuli. }\end{array}$ \\
\hline
\end{tabular}

The data collected then analyzed and described statistically. First, the level of mathematical literacy before and after culturally responsive mathematics teaching was analyzed to see the difference between experimental and control class. Then, the data analyzed to see the increasing/decreasing level of students' mathematical literacy before and after culturally responsive teaching.

\section{RESULTS AND DISCUSSIONS}

Students' mathematical literacy level was collected after the students taught by culturally responsive teaching. The results obtained show the level of mathematical literacy of students in culturally responsive mathematics class is significantly different than students who were not.

Table 4. Test of Normality of two classes

\begin{tabular}{cccccccc}
\hline \multirow{2}{*}{ Group } & & \multicolumn{3}{c}{$\begin{array}{c}\text { Kolmogrov- } \\
\text { Smirnov }\end{array}$} & \multicolumn{3}{c}{ Shapiro- Wilk } \\
\cline { 3 - 8 } & & Statistic & df & Sig. & Statistic & df & Sig. \\
\hline $\begin{array}{c}\text { Level of } \\
\text { Mathematical } \\
\text { Literacy }\end{array}$ & $\begin{array}{c}\text { Experim } \\
\text { ent }\end{array}$ & 215 & 24 & .006 & .899 & 24 & .021 \\
\cline { 2 - 8 } & Control & 224 & 29 & .001 & .852 & 29 & .001 \\
\hline
\end{tabular}


Both Kormogorov-Smirnov and Shapiro-Wilk statistics show p-value $<0.05$ for both classes. This means that the level of mathematics literacy of students after learning in both classes is not normally distributed.

Tabel 5. Homogenity test of mathematical Literacy

\begin{tabular}{rlcc}
\hline $\begin{array}{l}\text { Levene } \\
\text { Statistic }\end{array}$ & df1 & df2 & df3 \\
\hline $\mathbf{1 . 8 0 2}$ & 1 & 51 & 0.185 \\
\hline
\end{tabular}

Levene statistic 1.802 was obtained with $p$-value $=0.185>0.05$. This shows the level of students' mathematical literacy of after culturally responsive mathematics class has the same or homogeneous variant.

Table 6. Hypothesis test of Mathematical Literacy Level

\begin{tabular}{lc}
\hline & $\begin{array}{c}\text { Mathematical Literacy } \\
\text { Level } \\
\text { after Culturally } \\
\text { Responsive Teaching }\end{array}$ \\
\hline Mann-Whitney U & 242.000 \\
Wilcoxon W & 677.000 \\
Z & -1.990 \\
$\begin{array}{l}\text { Asymp.Sig. } \\
\text { tailed) }\end{array}$ & .047 \\
\hline
\end{tabular}

The Mann-Whitney value 242.0 was obtained with p-value (Asump. Sig. $(2$-tailed $))=0.047<0.05$. Because $p$-value is <significance level, $\mathrm{H}_{0}$ is rejected or $\mathrm{H}_{\mathrm{a}}$ is accepted. It was concluded that the level of students' mathematical literacy taught by culturally responsive mathematics different significantly from students who were not. Descriptively, the average level of students in culturally responsive mathematics class is higher than students who are not. This finding is in line with (Ojose, 2011) that stated that the culturally responsive teaching influence children's abilities in mathematics. Teachers must teach in such a way that conceptual understanding is obtained by students. This is the only way they will be able to apply mathematics learning in real life as an adult. Also, the content taught in school mathematics must reflect relevance to society. So that, students' doubt about where the mathematical material learned will be used in real life can be eliminated.

The findings in both experimental and control classes show that student dominance is still at level 1 and 2. This result is in agreement with the mathematical performance of 15-year-old students in Indonesia in 2015 with an average score on PISA is 386 . The score is still below the OECD countries average, which is 490. Table 7 showed the snapshots of students' performances during the culturally mathematics responsive teaching.

Table 7. Snapshots of Students' Performance in culturally mathematics responsive classroom

\begin{tabular}{lcc}
\hline & Before & After \\
\hline Number of Students & 24 & 24 \\
Level Maximum & 4 & 5 \\
Level Minimum & 1 & 1 \\
Mode & 2 & 3 \\
Average & 1.92 & 2.54 \\
Standard Deviation & 0.83 & 1.02 \\
\hline
\end{tabular}

Table 8. Snapshot of Mathematical literacy Level of Students taught by Culturally Responsive Mathematics Teaching

\begin{tabular}{|c|c|c|c|c|c|c|c|c|}
\hline \multirow{2}{*}{\multicolumn{2}{|c|}{$\begin{array}{c}\text { Literacy } \\
\text { level }\end{array}$}} & \multicolumn{6}{|c|}{ After CRM teaching } & \multirow[t]{2}{*}{ Total } \\
\hline & & 1 & 2 & 3 & 4 & 5 & 6 & \\
\hline \multirow{6}{*}{ 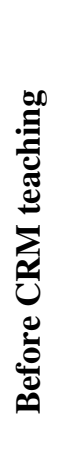 } & 1 & 4 & 4 & & & & & 8 \\
\hline & 2 & & 3 & 6 & 2 & & & 11 \\
\hline & 3 & & & 4 & & & & 4 \\
\hline & 4 & & & & & 1 & & 1 \\
\hline & 5 & & & & & & & 0 \\
\hline & 6 & & & & & & & 0 \\
\hline \multicolumn{2}{|c|}{ Total } & 4 & 7 & 10 & 2 & 1 & 0 & 24 \\
\hline
\end{tabular}


There were 8 students at level 1 (score 358- 419). According to PISA proficiency level, students at level 1 able to answering questions that involving familiar contexts where all relevant information is present and the questions are clearly defined. They also able to identify information and to carry out routine procedures according to direct instructions in explicit situations. Furthermore, students able to perform actions that are almost always obvious and follow immediately from the given stimuli. After culturally responsive mathematics teaching was implemented in the classroom, there were 4 students at this level, meanwhile, remain increase to $2^{\text {nd }}$ level of mathematical literacy.

Before culturally responsive mathematics teaching was implemented in the classroom, there were 11 students at level 2 (score $420-481$ ). At level 2, the students able to interpret and recognize situations in contexts that require no more than direct inference. The students also capable of extracting relevant information from a single source and make use of a single representational mode. Students at this level able to employ basic algorithms, formulae, procedures or conventions to solve problems involving whole numbers and making literal interpretations of the results. After culturally responsive mathematics teaching, only 3 students remain at this level, meanwhile, 6 students increase their level to $3^{\text {rd }}$ level and 2 to $4^{\text {th }}$ level of mathematical literacy.

Furthermore, before culturally responsive mathematics teaching was implemented in the classroom, 4 students were at $3^{\text {rd }}$ level of mathematical literacy (score 482-544). According to the proficiency of mathematical literacy level, students at this level capable of executing clearly described procedures, including those that require sequential decisions. They also able to made sufficiently sound interpretations to be a base for building a simple model or for selecting and applying simple problem-solving strategies. At this $3^{\text {rd }}$ level, the students able to interpret and use representations based on different information sources and reasoning directly from them. On the other hand, they are capable of showing some ability to handle percentages, fractions and decimal numbers, working with proportional relationships, and engaging in basic interpretation and reasoning. There were no students at this level who are able to increasing their mathematical literacy level to $4^{\text {th }}$ level. Unfortunately, after culturally responsive mathematics teaching was implemented, the students remain at level 3. But, there were 8 students increased from $2^{\text {nd }}$ level. Then, the number of students at $3^{\text {rd }}$ level is increase to 10 after culturally responsive mathematics teaching.

At level 4 (score 545 - 606), there was only 1 student that able to achieve this level. In mathematical literacy perspective, the student is capable of working effectively with explicit models of complex, concrete situations that may involve constraints. He or she was able to select and integrate different representations (including symbolic representations) and link them directly to aspects of real-world situations. Additionally, he/she able to use his/her limited range of skills and reasoning with some insight in straightforward contexts, construct, and communicate explanations and arguments based on his/her interpretations, arguments and actions. The $4^{\text {th }}$ level student is increasing his/her level to $5^{\text {th }}$ level of mathematical literacy after learning in culturally responsive mathematics classroom. In other words, there were 2 students at $4^{\text {th }}$ level after culturally responsive mathematics was implemented in the classroom. Before culturally responsive mathematics was implemented in the classroom, there was no students achieve the $5^{\text {th }}$ level of mathematical literacy (score 607 -668). 
Then, there was 1 student whose his/her level increased from $4^{\text {th }}$ level to $5^{\text {th }}$ level. As stated in the descriptions of the six levels of proficiency on the PISA 2015 mathematical literacy scale (Shiel et al., 2014), student at his level capable of developing and working with models of complex situations, including identifying constraints and specifying assumptions. $\mathrm{He} / \mathrm{she}$ also able to select, compare, and evaluate appropriate problem-solving strategies for dealing with complex problems related to these models. Moreover, he/she is capable of working strategically using broad, well-developed thinking and reasoning skills, appropriate linked representations, symbolic and formal characterizations and insights pertaining to these situations. In addition, the student begins to reflect on their work and formulating and communicating their interpretations and reasoning.

\section{CONCLUSION AND RECOMMENDATION}

Culturally responsive mathematic teaching gives positive effect to students' mathematical literacy.

The level of mathematical literacy of MAN 1 Takengon students were lie from level 1 to level 5. There was no student who bale to achieve $6^{\text {th }}$ level of mathematical literacy. After culturally responsive mathematic teaching implemented, from 24 students, there were 4 students at $1^{\text {st }}$ level, 7 students at $2^{\text {nd }}$ level, 10 students at $3^{\text {rd }}$ level, and 2 students at $4^{\text {th }}$ level, and 1 student at $5^{\text {th }}$ level of mathematical literacy.

\section{REFERENCES}

Ambrosio, U. D. (2014). Ethnomathematics and its place in the history and pedagogy of mathematics (Vol. 5). State University of New York Press.

Averill, R., Anderson, D., Easton, H.,
Maro, P. Te, Smith, D., Maro, P. Te, ... Smith, D. (2009). Culturally Responsive Teaching of Three Models from Mathematics: Linked Studies. Journal for Research in Mathematics Education, 40(2), 157186.

Bandeira, F. A., \& Lucena, I. C. R. (2004). Etnomatemática e práticas sociais [Ethnomat-hematics and social practices]. Coleção Introdução à Etnomate-mática[Introduction to Ethnomathematics Collection]. Natal, RN, Brazil: UFRN

Banks, J. A. (1992). Multicultural Education: Historical Development, Dimensions, and Practice.

Dossey, J. A. (1990). The nature of mathematics: Its role and its influence. Handbook of research on mathematics teaching and learning: A Project of the National Council of Teachers of Mathematics. In D. A. Grouws (Ed.) (pp. 39-48). New York: Macmillan.

Educators, A. of A. N. (1999). No Title. Alaska: Alaska Native Knowledge Network.

Gerdes, P. (1988). On culture, geometrical thinking and mathematics education. Educational Studies in Mathematics, 19(2), 137-162.

Gay, G. (2000). Culturally Responsive Teaching: Theory, Research, and Practice. New York, NY: Teachers College Press.34-35

Gutstein, E. (2003). Teaching and Learning Mathematics for Social Justice in an Urban, Latino School. Journal for Research in Mathematics Education, 34(1), 37-73. https://doi.org/10.2307/30034699

Herron, J., \& Barta, J. (2009). Herron, J., 
\& Barta, J. (2009). Culturally relevant word problems in second grade: What are the effects. Journal of Mathematics and Culture, 4(October 2009), 23-49.

Johar, R. (2012). Domain Soal PISA untuk Literasi Matematika. Jurnal Peluang, 1(1), 30-41.

Ladson-Billings, G . (1995). Making mathematics meaning fulin multicultural contexts. In W.G. Secada, E. Fennema \& L. Byrd (Eds.), New directions for equity in mathematics education. Cambridge, UK: Cambridge University. 126-145

Lobo, G., \& Torres-Velasquez, D. (2005). Culturally Responsive Mathematics Teaching and English Language Learner. Teaching Children Mathematics, 11(January), 249-255.

Morgan, C. (2001). MAthematics and human activity: representation in mathematical wriing. Journal Research in Mathematics Education, 3(14 April 2008), 37-41.

Mukhopadhyay, S., \& Greer, B. (2001). Modeling with purpose: Mathematics as a critical tool. Sociocultural research on mathematics education: An international perspective, 295311

Ojose, B. (2011). Mathematics Literacy: Are We Able To Put The Mathematics We Learn Into Everyday Use? Journal of Mathematics Education., 4(1), 89100.

Orey, D. C. (2000). The ethnomathematics of the Sioux tipi and cone. In $H$. Selin (Ed.), Mathematics across culture: the History of non-Western mathematics.

Dordrecht,
Netherlands: Kulwer Academic Publishers. $239-252$

Palomar, J. D., Simic, K., \& Varley, M. (2007). "Math is everywhere": Connecting mathematics to students' lives. Journal of Mathematics and Culture, 2(1), pp. 20-36.

Pewewardy,C.(1994).Culturallyrespo nsivepedagogyinaction:AnAme ricanIndianmagnetschool.InE. $\mathrm{R}$ .Hollins,J.E.King,\&W.C.Hayma $\mathrm{n}$ (Eds.),Teachingdiversepopulatio ns:Formulatingaknowledgebase (pp.77-

92).Albany,NY:StateUniversityof NewYork.

Rosa, M., \& Orey, D. C. (2011). Ethnomathematics: the cultural aspects of mathematics Etnomatemática : os aspectos culturais da matemática, 4, 32-54.

Rosa, M., Orey, D. C., Rosa, M., \& Orey, D. C. (2003). Culturally relevant pedagogy: an ethnomathematical approach, (1996), 19-31.

Shiel, G., Kavanagh, L., \& Millar, D. (2014). Proficiency levels in assessments of Reading and Mathematics. In The 2014 National Assessments of English Reading and Mathematics Volume 1: Performance Report. Dublin: Educational Research Centre.

Stacey, K. (2011). The PISA View of Mathematical Literacy in Indonesia. Journal of Research on Mathematics Education, 2(2), 95-126.

Torres-Velasquez, D., \& Lobo, G. (2004). Culturally Responsive Mathematics Teaching And English Language Learners. ,11,249-255.

Ukpokodu, O. N. (2011). How Do I Teach Mathematics in a Culturally 
Responsive Way?:Identifying Empowering Teaching Practices. Multicultural Education, 19(3), 4756.
Villegas, A. M., \& Lucas, T. (2002). Educating culturally responsive teachers: Acoherent approach. New York: State University of New York Press. 